\title{
Relationship between Managers' Performance and Organizational Health
}

\author{
Mohammadisadr, Mohammad \\ Scholar researcher, Educational administration, School of Educational Sciences and Psychology \\ University of Isfahan, 81746-73441, Isfahan, Iran \\ Tel: 98-913-144-3386 \\ Siadat, Seyyedali \\ Associate professor, Faculty of Education and Psychology, University of Isfahan, Isfahan, Iran \\ E-mail: s.a.siadat@edu.ui.ac.ir
}

Arbabisarjou, Azizollah (Corresponding author)

Faculty Member, Zahedan School of Nursing and Midwifery

Zahedan University of Medical Sciences, Zahedan, Iran

E-mail: Monireh_salti@yahoo.com

Received: December 31, 2011

Accepted: January 9, 2012 Online Published: May 22, 2012

doi:10.5539/ies.v5n3p228

URL: http://dx.doi.org/10.5539/ies.v5n3p228

\begin{abstract}
The main purpose of this paper is to study the relationship between managers' performance in the field of interpersonal, informational and decision-making tasks with organizational health. To measure the indicators of the model, a questionnaire was prepared and distributed among 113 company of Tehran stock Exchange Market. According to the results, there are a direct and significant relation between Interpersonal Roles, Informational Roles and Decision-making Roles with the Organizational Health at confidence level of 95\%. In addition, the relationship between Organizational Health and Job Satisfaction are confirmed at the same confidence level.
\end{abstract}

Keywords: Managers, Performance, Organization, Health

\section{Introduction}

Today, organizations are thought as organisms that have independent identity from their other members, so that with this new identity they can affect the behavior of employees. This personality and identity can be "organizational health" and/or "organizational illness". In order to have a healthy society, there should be created healthy organizations and to do so, first climate in the organization should be identified. For description and measurement of the social climate of the organizations, considerable scientific efforts have been made in recent decades. The organizational health is one of the famous and useful frameworks (Sharifi and Aghasi, 2010). Miles (1969) defined the organizational health. In his view, the organizational health $(\mathrm{OH})$ refers to the durability and survival in its environment and adapt to it and to upgrade and expand its ability to more adapt (Seyed Javadin et al, 2009).

Managers in organizations have duties that for perform these, should have clear understanding from the organizational roles and interpersonal and organizational goals, and in order to meet the needs of staff and clients all organizations try to deal successfully With internal and external forces to guide the destructive forces in order to maintain the organization (Sharifi and Aghasi, 2010). While managers often responsibility, strategy, technology, marketing and finance are delegated to subordinates successfully, but the responsibility of the organization culture health cannot delegated to nobody except herself. Therefore, the managers are one of the factors affecting to $\mathrm{OH}$. Hence, this study investigated the relationship between management performance and $\mathrm{OH}$. 


\section{Literature Review}

\subsection{Organizational Health}

Concept of organizational health is a unique or unprecedented concept which allows us to have a large image on organizational health. In healthy organizations, staff and personnel are committed, duty bounded and beneficial and enjoy high performance and spirit.

Health organization is a place where individuals rush to workplace with deep interest and boast to work at this place. In fact, health of organization plays a very constructive role in effectiveness of behavior of any system in terms of physical, mental, security, meritocracy and valuation to knowledge, specialty and personality of beneficiaries and boosting their capabilities and fulfilling duties delegated by its ultra-systems. In organizations which possess staff and personnel with organizational health personality, organizational justice is defined meaningfully and staff feels it with all their means wholeheartedly (Motevallizadeh and Zakiani, 2011).

Organizational health components are as follows:

1) Relationship: In a health organization, consecutive relation between staff and personnel should be facilitated appropriately the same with subordinates and senior officials. Relation should be mutual, details of which should be established in various levels of organization.

2) Contribution and Involving in Organization: In a health organization, staff and personnel of all levels should involve themselves with decision makings of organization.

3) Loyalty and commitment: In a health organization, there is a high trust and confidence among persons.

4) Validity, fame or prestige of organization: In a health organization, perceptions will reflect positive credit and prestige to staff, based on which, staff values and honors prestige and validity of their department or division.

5) Spirit: Appropriate spirit in organization is established in a friendly environment where staff likes each other and their jobs.

6) Ethics: In a health organization, generally, there is not immoral behavior. Staff desire to respect and value more to their inner ethics and conducts.

7) Recognition or cognition of performance: In a health organization, staffs are encouraged to actualize or materialize their talents and are supported. Generally, they feel that they are beneficial.

8) Path of Target: In a health environment, staff can recognize high concentration of their departments and distinguish objectives inside the organization, for; they contribute in formulation of objectives.

9) Leadership: Leaders are considered as determining factor on profitability and efficacy and effectiveness of organization. Leaders have generally friendly behavior and staff and personnel can establish relation with them in peace of mind and easily.

10) Improvement or development of performance of staff: in an organizational health environment, there is almost a special board for supporting training and consecutive improvement of existing manpower in organization.

11) Application of Resources: staff and personnel should observe that resources and facilities have divided among them deservedly and appropriately in accordance with their expectations on their progresses. In healthy organizations, system workforce especially staff and personnel are used effectively i.e. individuals are neither unemployed not work more than ordinary time (Motevallizadeh and Zakiani, 2011).

The concept of organizational health is a mixture of ideas from Parsons (1967), Miles (1969) and Etzioni (1990).

In 1969, Miles delineated 10 properties of healthy organizations. Those properties include goal focus, communication adequacy, optimal power equalization, resource utilization, cohesiveness, morale, innovativeness, autonomy, adaptation, and problem-solving adequacy. He divided these characteristics into three needs that organizations must fulfill: task, maintenance, and growth.

- Task needs deal with the way that information is transmitted and how decisions are made. The properties associated with task needs include goal focus, communication adequacy, and optimal power equalization.

- Maintenance needs refer to the internal workings of the organization, and the related properties are resource usage, cohesiveness, and morale.

- Growth needs deal with change in the organization, and the properties linked with them are innovativeness, autonomy, adaptation, and problem-solving adequacy. 
Parsons (1967) stated that in order for organizations to survive, grow, and prosper, they must solve the four basic problems of adaptation, goal attainment, integration, and latency.

Etzioni (1990) narrowed these four functions to two: (1) instrumental needs of input and allocation (adaptation and goal attainment) and (2) expressive needs of social and normative integrations (integration and latency) (Teresa, et al., 2005).

\subsection{Performance of Managers}

Mintzberg (1971) proposed that differences in managerial performance involve the relative importance of the roles across hierarchical level and functional specialty (Pavett and Lau, 1983). He concluded that what managers do can best be described by looking at 10 different but highly interrelated management roles they use at work( Robbins and Coulter, 2007). Managers perform ten basic roles which fall into three groupings. The interpersonal roles describe the manager as figurehead, external liaison, and leader; the information processing roles describe the manager as the nerve center of his organization's information system; and the decision-making roles suggest that the manager is at the heart of the system by which organizational resource allocation, improvement, and disturbance decisions are made (Mintzberg, 1971). These roles are common to the performance all managers (Pavett and Lau, 1983). The definitions of roles in follow are presented:

Interpersonal Roles: Mintzberg's interpersonal roles are primarily social in nature; that is, they are roles in which the manger's main task is to relate to other people in certain ways. The manager sometimes many serve as a figurehead for the organization. Taking visitors to dinner and attending ribbon-cutting ceremonies are part of the figurehead role. In the role of leader, the manager works to hire, train, and motivate employees. Finally, the liaison role consists of relating to others outside the group or organization. For example, a manager at Intel might be responsible for handling all price negotiations with a major supplier of electronic circuit boards. Obviously, each of these interpersonal roles involves behavioral processes.

Informational Roles: Mintzberg's three informational roles involve some aspects of information processing. The monitor actively seeks information that might be of value to the organization in general or to specific managers. The manager who transmits this information to others is carrying out the role of disseminator. The spokesperson speaks for the organization too outsiders.

Decision-making Roles: Finally, Mintzberg identified four decision-making roles. The entrepreneur voluntarily initiates change, such as innovations or new strategies, in the organization. The disturbance handler helps settle disputes between various parties, such as other mangers and their subordinates. The resource allocator decides who will get what-how resources in the organization will be distributed among various individuals and groups. The negotiator represents the organization in reaching agreements with other organizations, such as contracts between management and labor unions. Again, behavioral processes are clearly crucial in each of these decisional roles (Understanding and managing organizational behaviour, 2006). Also, effectiveness and commitment of leadership can lead organization from unfavorable situation to optimum (Victoria, 2000). Therefore, the performance of managers can influence organizational health.

Given the above, the manager can only provide health to the organization. In this paper, the managers' performance is studied with use of managerial roles to investigate its impact on the dimensions of organizational health. For this purpose, the following hypotheses are offered:

H1: There is a significant relationship between managers' performance in the field of interpersonal tasks with organizational health.

$\mathrm{H} 2$ : There is a significant relationship between managers' performance in the field of informational tasks with organizational health.

H3: There is a significant relationship between managers' performance in the field of decision-making tasks with organizational health.

H4: There is a significant relationship between organizational health with Job Satisfaction.

Base on the above relationships we can consider the final Model as no figure (1).

Inset Figure 1 about here.

\section{Methodology}

In order to test the research hypothesis, the researcher distributed a questionnaire among 113 managers, deputies and experts of Tehran stock Exchange Market who were asked about the importance of indices and variables in the 
questionnaire. The importance of each item was defined according to a 1 to 5 scale in which 1 meant minimum importance and 5 meant maximum importance.

With respect to the model, presented in the previous section, the model has been estimated using PLS Path Modeling Technique. For this purpose, Visual PLS1.04 was used.

\section{Data Analysis}

In this section, with respect to the model, presented in the previous section, the model has been estimated and its validity was examined using PLS Path Modeling Technique.

First, after extracting the answers, manifest variables were normalized as fallows:

The original items Yi, scaled from 1 to 5 , are transformed into new normalized variables $X_{i}=\frac{100}{4}\left(Y_{i}-1\right)$.

The minimum possible value of $X_{i}$ is 0 and its maximum possible value is equal to 100 . If there are missing data for variable $X_{i}$, they are replaced by the mean of this variable.

After specifying the relationship between the variables of the model, using PLS Path Modeling Technique, all the coefficients and parameters were estimated. For this purpose, vpls1.04 software was used to estimate the relationship between the latent variables of the problem.

Insert Figure 2 about here.

A PLS path model consists of a structural model and a measurement model. Then, the validation of a PLS path model requires the analysis and interpretation of both the structural and the measurement model. This validation can be considered as a two-stage process: the assessment of the measurement model, and the assessment of the structural model. (Henseler et al, 2009).

\subsection{Assessing the Structural Model}

According to Chin's theory, $\mathrm{R}^{2}$, that is just measured for endogenous variables and shows the variance of endogenous latent variables, can be interpreted as noticeable, average and weak for values of 0.67, 0.67-0.33 and less that 0.19 respectively. Also, in a specific model including endogenous latent variables with only one or two exogenous latent variable(s), average amount of $\mathrm{R}^{2}$ is acceptable (Trujillo, 2009). In this study, $\mathrm{R}^{2}$ value is equal to 0.605 . Therefore, $\mathrm{R}^{2}$ value of the model is acceptable.

\subsection{Assessing Measurement Models}

In this section, we must evaluate three aspects of reflective measures

- Unidimensionality of the indicators

- $\quad$ Check that indicators are well explained by its latent variable

- $\quad$ Assess the degree to which a given construct is different from other constructs

4.2.1 Unidimensionality of the Indicators

Some recent tools have been proposed to evaluate unidimensionality of PLS-PM reflective blocks (Sahmer et al, 2005), but the most common methods employed for this purpose are the following three indicators:

- Check the first eigenvalue of the MVs correlation matrix

- Calculate the Cronbach's alpha

- Calculate the Dillon-Goldstein's

In this paper, Unidimensionality of the indicators was measured using Cronbach's alpha coefficient. If the coefficient is more than 0.7 the reliability of the model is high and if the coefficient is smaller than 0.6 , the model has low reliability (Henseler et al, 2009). Although Cronbach's alpha coefficient for IPR is less than 0.6, but the average of Cronbach's $\alpha$ coefficients of the model is higher than 0.7 , showing that the reliability of the model is confirmed in general (table2).

\subsubsection{Check That Indicators are Well Explained by Its Latent Variable}

In this case, we check it by means of two tools:

\section{- Composite Reliability}

Composite Reliability is the criterion of the model reliability. For this criterion, value less than 0.6 , indicating a lack of reliability (Henseler et al, 2009).

The value of this criterion in this study is much more than 0.6 , which shows the high reliability of the model (table 2). 
- $\quad$ AVE

To calculate the convergent validity, Fornell and Larcker suggested AVE. AVE should be larger than 0.50 which means that $50 \%$ or more variance of the indicators should be accounted for (Henseler et al, 2009).

The AVE of the model is higher than 0.5 ; so the convergent validity of the model is confirmed.

Insert Table 1 about here.

4.2.3 Assess the Degree to Which a Given Construct is Different from Other Constructs

We evaluate the extent to which a given construct differentiates from the others. This is done by verifying that the shared variance between a construct and its indicators is larger than the shared variance with other constructs. In other words, no indicator should load higher on another construct than it does on the construct it intends to measure. We calculate the correlations between a construct and other indicator besides its own block. If an indicator loads higher with other constructs than the one it is intended to measure, we might consider its appropriateness because it is not clear which construct or constructs it is actually reflecting(Henseler et al, 2009).

On this basis, $\mathrm{OH} 5, \mathrm{OH} 9$ have not been identified as appropriate indicators for latent variables and were excluded from the model; however the other indicators of the model were confirmed.

Insert Table 2 about here.

On the other hand, all measurement indicators have explained their own Latent variable correctly.

\section{Conclusion and Discussion}

Based on the presented model, the relationship between the Interpersonal Roles, Informational Roles and Decision-making Roles with the Organizational Health at confidence level of $95 \%$ are confirmed. Also the relationship between Organizational Health and Job Satisfaction are confirmed at confidence level of 95\%.

However, the Organizational Health has been mostly affected by the Interpersonal Roles $(0.608)$. Then, the variables Decision-making Roles and Informational Roles have had impact on the Organizational Health respectively.

Insert Table 3 about here.

\section{References}

E. Dalton. (2005)." Level Schools Organizational Health and Student Achievement in Tennessee Middle”. pp1-24.

Etzioni, A. (1990). Modern organizations. Englewood Cliffs NJ: Prentice Hall.

Henslere, C. L., Buehler, Alison E., Stein, W. L., Dalton, J. E., Robinson, T. R., \& Anfara JR, V. A. (2009). Organizational Health and Student Achievement in Tennessee Middle Level Schools. NASSP Bulletin 2005; 89; 54.

Los Alamitos, California (2006). Delta Publishing .Understanding and managing organizational behaviour, [Online] Available: http://www.apexcpe.com/publications/471001.pdf (November 5, 2011)

Miles, M. B. (1969). "Planned change and organizational health: figure and ground” in Carver, E. A., Sergiovanni, T. J. (Eds.) Organizations and Human Behaviour. McGraw-Hill, New York: NY, 375-91

Mintzberg, H. (1971). "Managerial work: analysis from observation". Management Science, 18(2), http://dx.doi.org/10.1287/mnsc.18.2.B97

Motevallizadeh, S., \& Zakiani, S.H. (2011). "Studying role of organizational justice and organizational health personality in Deputy of Research and Technology", Ministry of Health and Medical Education, Tehran, Iran.

Parsons, T. (1967). Some ingredients of a general theory of formal organization. In A. W. Halpin (Ed.), Administrative theory in education. New York: MacMillan.

Pavett, C., \& Lau, A. (1983). "Managerial Work: The Influence of Hierarchical Level and Functional Specialty”, The Academy of Management Journal, 26(1), pp. 170-177. http://dx.doi.org/10.2307/256144

Robbins, S., \& Coulter, M. (2007). “Management with Rolls Access Code”, Ninth Edition, Published by Prentice Hall.

Sahmer, K., Vigneau, E., \& Qannari, E. M. (2005). A cluster approach to analyze preference data: Choice of the number of clusters. Food Quality and Preference, 17, 257-265.

Seyed Javadin, R., Alavi, A., \& Ansari, Sh. (2011). "Organizational Health Index in Isfahan University of Medical Sciences(IUMS)”, Journal of Health Administration, 13(41), pp.63-81.

Sharifi, A., \& Aghasi, S. (2010). "The study of relationship between manager's performance and organizational health", Scientific and Research Journal of new approach in educational management, 4, pp.149-167. 
Teresa, R., Robinson, A., Vincent A., Anfara, J.R., Christopher, L., Henderson, A. E., Buehler, W. L., Stein, J., \& Victoria, D. (2000). "Principal Leadership for Equity and excellence: A Case study of an Inclusive Exemplary School", PHD dissertation, University of Houston.

Trujillo, C.A. (2009). Effects of Perceived Utility from Categorical vs. Quantitative attributes in Choice Trabajo para optar al título de D.E.A. Universitat Pompeu Fabra.

Table 1. Reliability and AVE

\begin{tabular}{|l|l|l|l|}
\hline Construct & $\begin{array}{l}\text { Composite } \\
\text { Reliability }\end{array}$ & AVE & Cronbach Alpha \\
\hline IPR & 0.74 & 0.53 & 0.58 \\
\hline IFR & 0.86 & 0.67 & 0.76 \\
\hline DMR & 0.84 & 0.63 & 0.70 \\
\hline OH & 0.83 & 0.46 & 0.74 \\
\hline JS & 0.78 & 0.64 & 0.63 \\
\hline
\end{tabular}

Table 2. Correlation of Manifest and Latent Variables of the Model

\begin{tabular}{|l|l|l|l|l|l|}
\hline Items & IRR & IFR & DMR & OH & JS \\
\hline IPR1 & $\mathbf{0 . 5 1 3 8}$ & 0.3523 & 0.2116 & 0.0554 & 0.2764 \\
\hline IPR2 & $\mathbf{0 . 8 0 6 3}$ & 0.5503 & 0.2127 & 0.2053 & 0.4802 \\
\hline IPR3 & $\mathbf{0 . 8 5 3 5}$ & 0.4217 & 0.3520 & 0.4058 & 0.0838 \\
\hline IFR1 & 0.2222 & $\mathbf{0 . 6 1 8 2}$ & 0.5854 & 0.1979 & 0.0426 \\
\hline IFR2 & 0.5836 & $\mathbf{0 . 8 1 1 3}$ & 0.5800 & 0.1891 & 0.2160 \\
\hline IFR3 & 0.0505 & $\mathbf{0 . 2 8 2 6}$ & 0.2307 & 0.1388 & 0.0459 \\
\hline DMR1 & 0.4549 & 0.2174 & $\mathbf{0 . 7 1 7 4}$ & 0.2107 & 0.2772 \\
\hline DMR2 & 0.0371 & 0.0470 & $\mathbf{0 . 1 8 1 3}$ & 0.0667 & 0.0978 \\
\hline DMR3 & 0.2868 & 0.5922 & $\mathbf{0 . 9 5 5 1}$ & 0.6181 & 0.4360 \\
\hline OH1 & 0.5236 & 0.4762 & 0.3917 & $\mathbf{0 . 8 4 9 0}$ & 0.4242 \\
\hline OH2 & 0.2418 & 0.1658 & 0.2265 & $\mathbf{0 . 6 6 5 0}$ & 0.1213 \\
\hline OH3 & 0.4725 & 0.3181 & 0.3906 & $\mathbf{0 . 9 7 0 9}$ & 0.3838 \\
\hline OH4 & 0.0937 & 0.2068 & 0.0278 & $\mathbf{0 . 3 6 0 6}$ & 0.0524 \\
\hline OH6 & 0.4576 & 0.3583 & 0.5063 & $\mathbf{0 . 6 2 5 7}$ & 0.3434 \\
\hline OH7 & 0.1764 & 0.4416 & 0.0132 & $\mathbf{0 . 6 8 9 1}$ & 0.3553 \\
\hline OH8 & 0.1565 & 0.3770 & 0.3528 & $\mathbf{0 . 4 9 2 9}$ & 0.1412 \\
\hline OH10 & 0.5506 & 0.5487 & 0.6599 & $\mathbf{0 . 8 2 3 0}$ & 0.4736 \\
\hline OH11 & 0.4038 & 0.5873 & 0.5707 & $\mathbf{0 . 8 5 0 4}$ & 0.6992 \\
\hline JS1 & 0.0976 & 0.0400 & 0.1264 & 0.1306 & $\mathbf{0 . 3 4 0 6}$ \\
\hline JS2 & 0.1813 & 0.6071 & 0.4843 & 0.4965 & $\mathbf{0 . 9 1 6 1}$ \\
\hline
\end{tabular}


Table 3. Structural Model

\begin{tabular}{|l|l|l|l|l|}
\hline & $\begin{array}{l}\text { Entire } \\
\text { Sample } \\
\text { estimate }\end{array}$ & $\begin{array}{l}\text { Mean of } \\
\text { Subsamples }\end{array}$ & $\begin{array}{l}\text { Standard } \\
\text { error }\end{array}$ & T-Statistic \\
\hline IPR->OH & 0.6080 & 0.6068 & 0.0922 & 6.5932 \\
\hline IFR->OH & 0.2350 & 0.2302 & 0.0890 & 2.6400 \\
\hline DMR->OH & 0.2560 & 0.2713 & 0.1020 & 2.5100 \\
\hline OH- $>$ JS & 0.6840 & 0.6938 & 0.0921 & 7.4293 \\
\hline
\end{tabular}

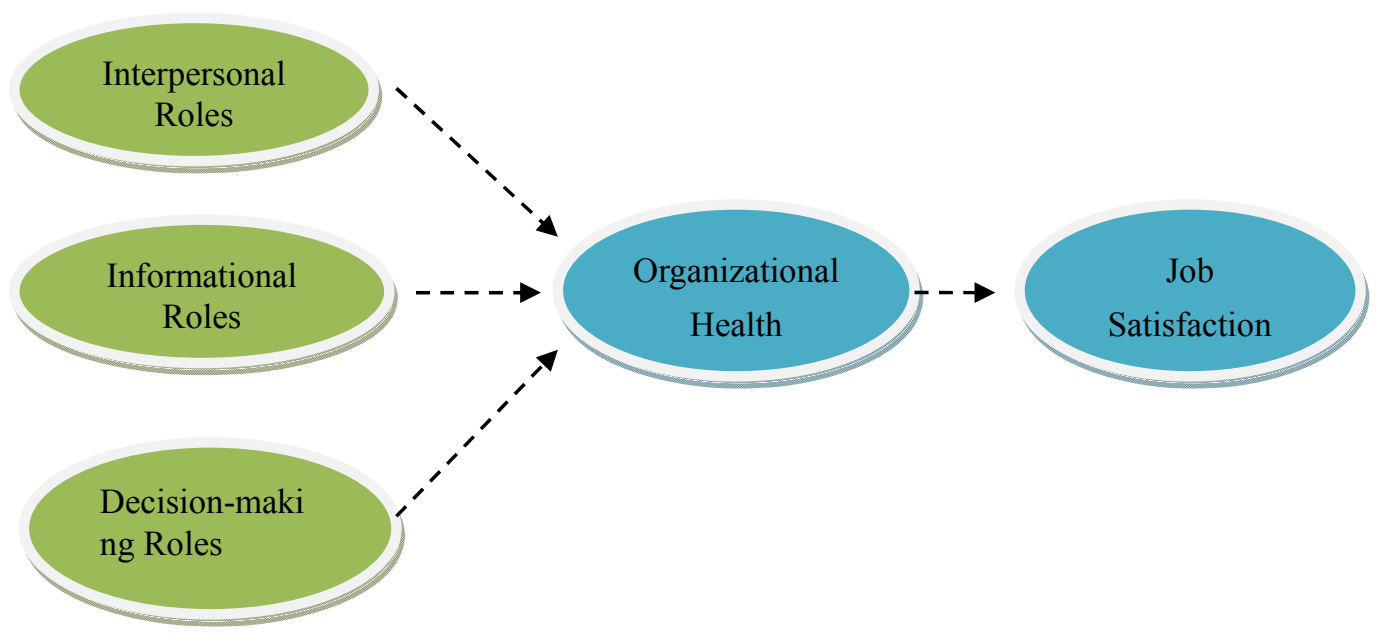

Figure 1. Relationship between the variables of the model

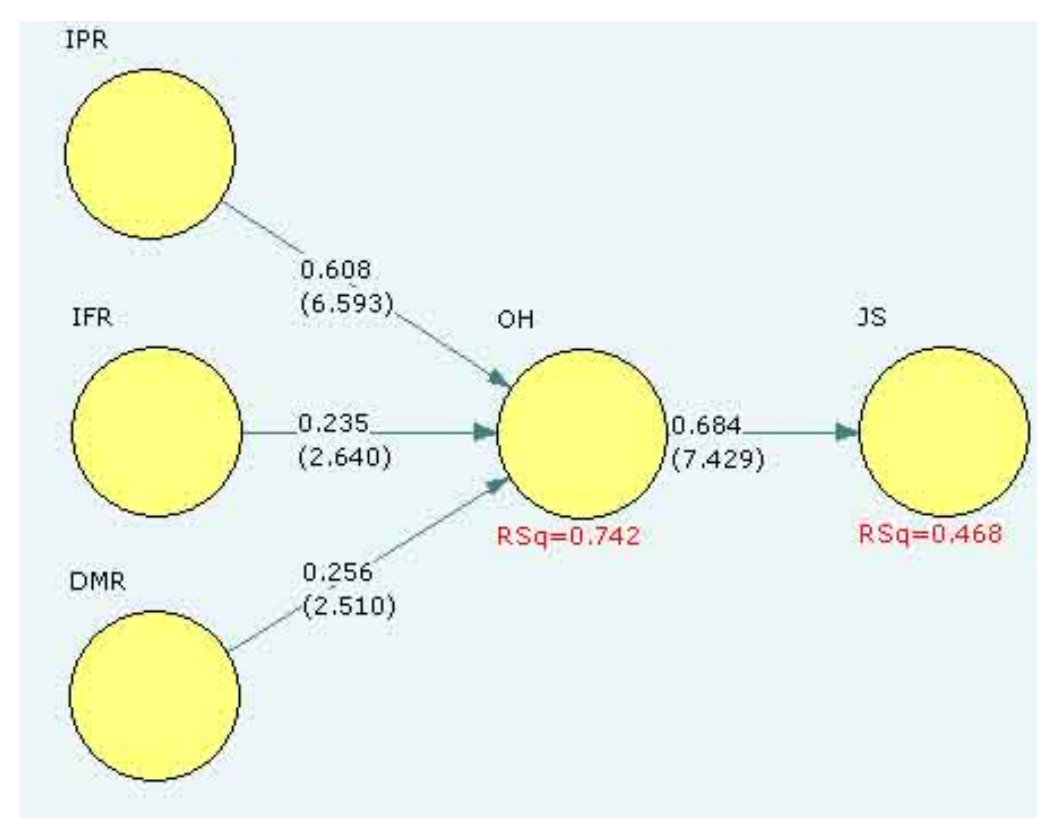

Figure 2. estimated model using VPLS 